\title{
A 350 ka record of climate change from Lake El'gygytgyn, Far East Russian Arctic: refining the pattern of climate modes by means of cluster analysis
}

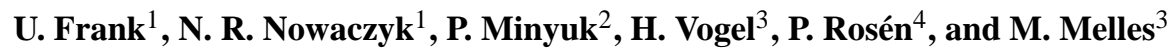 \\ ${ }^{1}$ Helmholtz Centre Potsdam, GFZ German Research Centre for Geosciences, \\ Section 5.2 - Paleoclimate and Landscape evolution, 14473 Potsdam, Germany \\ ${ }^{2}$ North-East Interdisciplinary Science Research Institute, FEB RAS, 685000 Magadan, Russia \\ ${ }^{3}$ Institute of Geology and Mineralogy, University of Cologne, 50674 Cologne, Germany \\ ${ }^{4}$ Climate Impacts Research Centre (CIRC), Umeå University, 98107 Abisko, Sweden \\ Correspondence to: U. Frank (ufrank@gfz-potsdam.de)
}

Received: 5 September 2012 - Published in Clim. Past Discuss.: 17 October 2012

Revised: 30 May 2013 - Accepted: 17 June 2013 - Published: 22 July 2013

\begin{abstract}
Rock magnetic, biochemical and inorganic records of the sediment cores PG1351 and Lz1024 from Lake El'gygytgyn, Chukotka peninsula, Far East Russian Arctic, were subject to a hierarchical agglomerative cluster analysis in order to refine and extend the pattern of climate modes as defined by Melles et al. (2007). Cluster analysis of the data obtained from both cores yielded similar results, differentiating clearly between the four climate modes warm, peak warm, cold and dry, and cold and moist. In addition, two transitional phases were identified, representing the early stages of a cold phase and slightly colder conditions during a warm phase. The statistical approach can thus be used to resolve gradual changes in the sedimentary units as an indicator of available oxygen in the hypolimnion in greater detail. Based upon cluster analyses on core Lz1024, the published succession of climate modes in core PG1351, covering the last $250 \mathrm{ka}$, was modified and extended back to $350 \mathrm{ka}$. Comparison to the marine oxygen isotope $\left(\delta^{18} \mathrm{O}\right)$ stack LR04 (Lisiecki and Raymo, 2005) and the summer insolation at $67.5^{\circ} \mathrm{N}$, with the extended Lake El'gygytgyn parameter records of magnetic susceptibility $\left(\kappa_{\mathrm{LF}}\right)$, total organic carbon content (TOC) and the chemical index of alteration (CIA; Minyuk et al., 2007), revealed that all stages back to marine isotope stage (MIS) 10 and most of the substages are clearly reflected in the pattern derived from the cluster analysis.
\end{abstract}

\section{Introduction}

The climate history of the Chukotka peninsula, Far East Russian Arctic, for the last $250 \mathrm{ka}$ was revealed by a multidisciplinary study on sediment core PG1351 from Lake El'gygytgyn (see Brigham-Grette et al., 2007, and references therein). Based on the interpretation of its sediment composition, physical properties, geochemistry, and organic components, four different climate modes were distinguished: warm, peak warm, cold and dry, and cold and wet (Melles et al., 2007). The individual climatic phases correspond to stages and substages of the marine isotopic record, when tuning the records of sediment variability to the Northern Hemisphere insolation (Melles et al., 2007; Nowaczyk et al., 2007). Additional information on the climatic history was provided from pollen counting (Lozkhin et al., 2007) and diatom analysis (Cherapanova et al., 2007) as well as sedimentological investigations (Asikainen et al., 2007).

Prior efforts to interpret core PG1351 in terms of specific climate modes (Melles et al., 2007) have not attempted to differentiate among apparent compositional variations that exist within intervals assigned to warm climate modes, or to identify possible transitional phases between peak warm and cold intervals. A statistical approach to the analysis of the existing data from core PG1351 and new rock magnetic and geochemical data from a second, longer core, Lz1024, thus provides a method for further refining the modes of variability evident in the sediments of Lake El'gygytgyn. The 

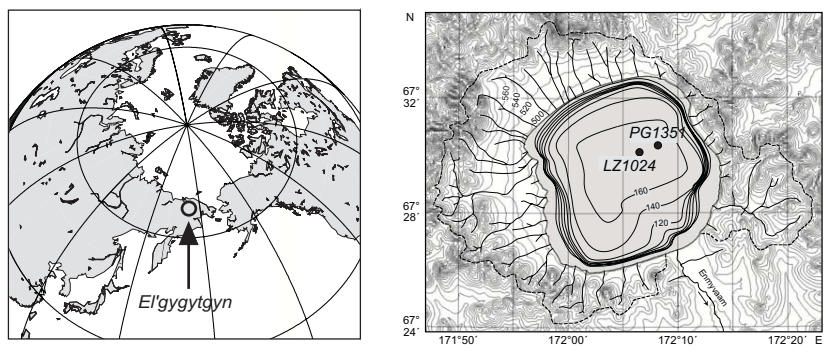

Fig. 1. Location of Lake El'gygytgyn (circle, not to scale) on the Chukotka peninsula, Far East Russian Arctic (left) and close up of the lake with the watershed (dashed line, contour interval for topography is $20 \mathrm{~m}$ ) and the locations of the sediment cores investigated (right).

reproducibility of the statistical approach to facies identification used in this study is evaluated by comparison of the results obtained from analysis of the individual cores. Cores PG1351 and Lz1024 are analysed in the context of revised age models now available for both cores (Nowaczyk et al., 2012, 2013), extending the existing record of environmental history of the Chukotka peninsula back to $350 \mathrm{ka}$. In addition the development of an objective and quantitative method of sedimentary facies analysis provides a framework for ongoing and future interpretation of the record now available from the International Continental Scientific Drilling Program (ICDP) core 5011-1 recovered from Lake El'gygytgyn in 2009.

\section{Settings and material}

Lake El'gygytgyn is located in central Chukotka, Far East Russian Arctic $\left(67^{\circ} 30^{\prime} \mathrm{N}, 172^{\circ} 05^{\prime} \mathrm{E}\right)$, in the zone of hypoarctic tundra, about $100 \mathrm{~km}$ to the north of the Arctic Circle (Fig. 1). The roughly circular lake with a diameter of $12 \mathrm{~km}$ and a maximum water depth of $175 \mathrm{~m}$ lies within a 3.58 ( \pm 0.04$)$ Ma-old meteoritic crater (Layer, 2000). The rocks in the lake catchment consist primarily of igneous rocks, lava, tuffs, ignimbrites of rhyolites and dacites, rarely andesites and andesitic tuffs (Gurov and Koeberl, 2004) of Upper Cretaceous age. Chemical and physical weathering products of these rocks make up the majority of the clastic material transported into the lake by about 50 ephemeral creeks originating from the crater rim. Weathering of the rocks is largely controlled by the presence or absence of permafrost (Minyuk et al., 2007). Fluvial transport and sedimentation is limited to summer periods when air temperatures are above $0^{\circ} \mathrm{C}$ and the ice cover on the lake is disintegrating (Nolan and Brigham-Grette, 2002).

During expeditions in 1998 and 2003, designed as pilot studies for the ICDP-drilling of Lake El'gygytgyn, two long sediment cores, PG1351 and Lz1024, were recovered from the lake centre at a water depth of $175 \mathrm{~m}$ (Fig. 1). Both cores were recovered during the springtime through holes in the lake ice, using a gravity corer (UWITEC Ltd., Austria) for the sediment water interface and a $3 \mathrm{~m}$-long percussion piston corer (UWITEC Ltd., Austria) for the deeper sediments (Melles et al., 2005, 2007). The core segments are overlapping, yielding two composite profiles with lengths of $1291 \mathrm{~cm}$ for PG1351 and $1660 \mathrm{~cm}$ for Lz1024. The sediment consists of alternations of brownish and greenish nonlaminated and laminated greyish silt and clay; including some turbidites with thicknesses of up to $45 \mathrm{~cm}$ (Juschus et al., 2009). Former investigations on core PG1351 (Nowaczyk et al., 2002, 2007; Melles et al., 2007; Minyuk et al., 2007) revealed that anoxic and laminated conditions primarily occur during periods of perennial ice cover and oxic and nonlaminated conditions occur when open water controls mixing of the water body during summer times (Melles et al., 2007). In intervals with prevailing anoxic conditions reductive dissolution of magnetite was observed whereas organic matter is well preserved. Biogenic productivity within the lake, controlled by availability of light and nutrients, also strongly depends on the duration of ice-free conditions and nutrient input from thawing permafrost soils during summer times.

\section{Methods}

\subsection{Rock magnetic analyses}

The magnetic susceptibility was measured on the split halves of the cores in $1 \mathrm{~mm}$ steps with a Bartington MS2E/1 spotreading sensor integrated in an automated core logging system (Nowaczyk et al., 2002). Magnetic susceptibility $\left(\kappa_{\mathrm{LF}}\right)$ of discrete samples $(20 \times 20 \times 15 \mathrm{~mm})$ was measured nearly continuously, taken along the $z$ axis of the core halves with an AGICO kappabridge KLY-3S. Isothermal remanent magnetizations (IRM) on the samples from core Lz1024 were imprinted with a $2 \mathrm{G}$ ENTERPRISES 660 pulse magnetizer and measured with a MOLYNEUX MiniSpin fluxgate magnetometer (noise level $0.2 \mathrm{mAm}^{-1}$ ). A field of $1500 \mathrm{mT}$ was chosen to imprint the saturation isothermal remnant magnetization (SIRM) of all samples, followed by a backfield (BF) of $-300 \mathrm{mT}$. The SIRM and backfield measurements for core PG1351 were performed with a Princeton measurement alternating gradient magnetometer (AGM) on an additional set of mini-samples with a volume of about $15-20 \mathrm{~mm}^{3}$ (see Nowaczyk et al., 2002, for details). S-ratios were calculated as $0.5 \times\left(1-\left(\mathrm{IRM}_{\mathrm{BF}} / \mathrm{SIRM}\right)\right)$ following Bloemendal et al. (1992).

\subsection{Geochemical analyses}

Inorganic geochemical analysis on core Lz1024 sediment were conducted on samples taken in steps of about $5 \mathrm{~cm}$. Major elements were analysed using a multi-channel X-ray fluorescence (XRF) spectrometer SRM-25 (USSR). Sample preparation followed the routine described in detail for 


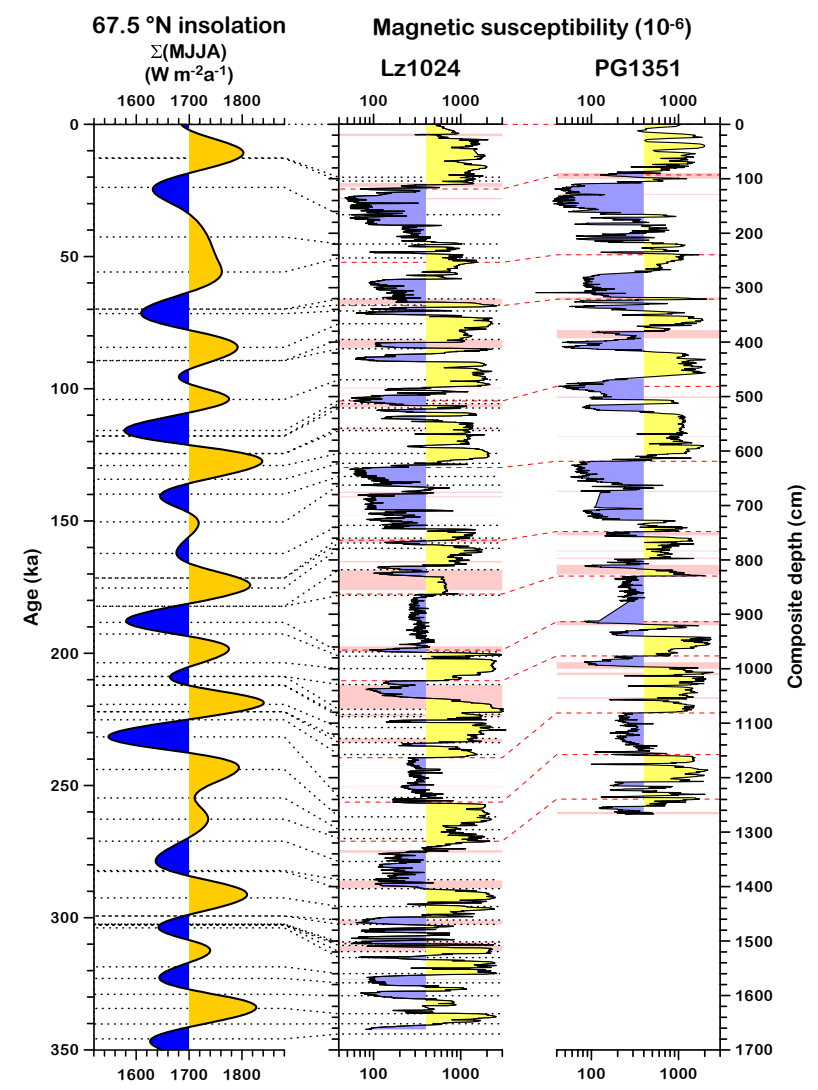

Fig. 2. Correlation of composite cores PG1351 and Lz1024 from Lake El'gygytgyn by means of high-resolution records of magnetic susceptibility, and tuning of these logs to the summer insolation at $67.5^{\circ} \mathrm{N}$ according to Laskar et al. (2004) (left). The tuning procedure is described in detail in Nowaczyk et al. (2012, 2013). Some prominent correlation levels are marked by dashed red lines. Pink bars denote turbidite layers.

analysis of the neighbouring core PG1351 (Minyuk et al., 2007). A selected group of major elements was used to quantify the degree of alteration utilizing the "chemical index of alteration", where $\mathrm{CIA}=\left[\mathrm{Al}_{2} \mathrm{O}_{3} /\left(\mathrm{Al}_{2} \mathrm{O}_{3}+\mathrm{CaO}+\mathrm{Na}_{2} \mathrm{O}+\right.\right.$ $\left.\left.\mathrm{K}_{2} \mathrm{O}\right)\right] \times 100$.

Biogeochemical analyses on core PG1351 were performed on freeze-dried samples continuously subsampled in $2 \mathrm{~cm}$ intervals (Melles et al., 2007). The content of total organic carbon (TOC) was determined with a CHNS-932 analyser, whereas biogenic silica (BSi) content was measured by a wet chemical method following Müller and Schneider (1993). On core Lz1024, the quantification of BSi and TOC was undertaken by Fourier Transform Infrared Spectroscopy (FTIRS) on samples taken in intervals of $1 \mathrm{~cm}$ as described by Rosén et al. (2010a). Reproducibility of the analyses is confirmed by the comparison with the BSi values obtained on a subset of samples by conventional measurements (Rosén et al., 2010a, b).

\subsection{Cluster analysis}

The rock magnetic and geochemical data obtained from cores PG1351 and Lz1024 were subject to a hierarchical agglomerative cluster analysis in order to discriminate sediment facies of characteristic composition and compare them with facies defined in core PG1351 on the basis of visual comparison of proxy data (Melles et al., 2007). This method is commonly used for sediment analysis in terms of spatial distribution of metal and heavy metal pollution (e.g. Danielsson et al., 1999; Simeonov et al., 2000). Former application of this statistical method on rock magnetic data from the Dead Sea sediments revealed that it is particularly suited for grouping sediment samples with similar composition from a set of geophysical and geochemical variables (Frank et al., 2007). In addition the resulting clusters can be presented in colour and symbolcoded within standard plots, thus visualizing the influence of the single parameters on the cluster formation. Cluster analysis was performed on the same set of parameters available for each core that are $\kappa_{\mathrm{LF}}$ the S-ratio, $\mathrm{BSi}, \mathrm{TOC}, \mathrm{Ti}_{2}$ and CIA, all of which are defined independently of each other. Thus the cluster-analysis was not biased by an emphasis on rock magnetic, inorganic or biogeochemical data. To obtain the same sample depths for all parameters taken from one core, the records of $\kappa_{\mathrm{LF}}$, S-ratio, TOC and BSi were re-sampled by interpolating between given values at depth associated with the existing inorganic geochemistry samples. Samples originating from turbidites (Juschus et al., 2009) were excluded from the statistical analysis. The routine was performed with WinSTAT for Excel (R. Fitch Software, 2003). The logarithm of the bulk susceptibility was taken for statistical analysis because values vary over more than one order of magnitude. All parameters were then standardized yielding a variance of 1 and a mean value of 0 . The Euclidean distance was computed and used as a measure of similarity between the pairs of data points. The used agglomerations method is called incremental sums of squares: the distance between two clusters is proportional to the changes of the sum of squares within the groups during formation of the different groups.

\subsection{Correlation and chronology}

In order to create the composite cores from the sediments recovered at sites PG1351 and Lz1024, overlapping core segments were correlated based upon high-resolution logs of magnetic susceptibility, the lithology and the physical and biogeochemical properties. Similarly, these variables were used to correlate core PG1351 with the longer core Lz1024, transforming the field depth of PG1351 to the depth scale of LZ1024, defined as the standard for this study (Fig. 2). Turbidites and volcanic ash layers acted as marker layers. Additional information, especially in the uppermost $200 \mathrm{~cm}$ of the cores, was provided by the parameters TOC and BSi. A total of 129 correlation levels were identified. Since Lz1024 


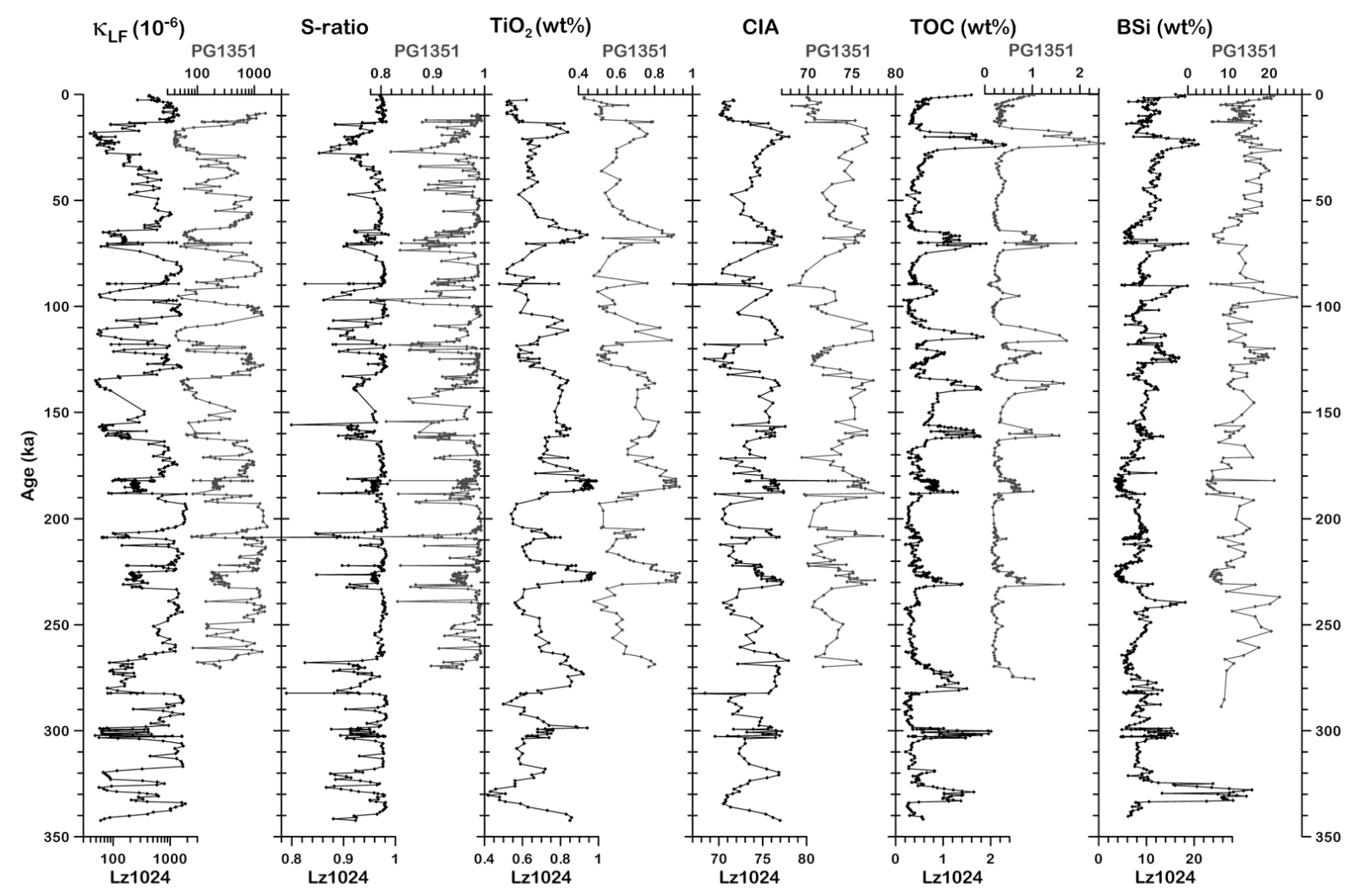

Fig. 3. Comparison of the records of magnetic susceptibility $\left(\kappa_{\mathrm{LF}}\right)$, S-ratio, $\mathrm{TiO}_{2}$ content, chemical index of alteration (CIA), total organic carbon (TOC) content, and content of biogenic silicium (BSi) for cores PG1351 and Lz1024 from Lake El'gygytgyn. All records are plotted versus age.

is integrated in the long record of ICDP Site 5011-1 this correlation is also valid for PG1351 and the 5011-1 record.

The depth-age model was derived from the systematic tuning of magnetic susceptibility, $\mathrm{BSi}$, TOC, and $\mathrm{TiO}_{2}$ to the Northern Hemisphere insolation (Fig. 2), considering also OSL dating from core PG1351 (Nowaczyk et al., 2002, 2007; Forman et al., 2007) and Lz1024 (Juschus et al., 2007). This method was also applied to the core composite from ICDP Site 5011-1 (Nowazcyk et al., 2013). Applying this method to cores Lz1024 and PG1351 yielded an age of $350 \mathrm{ka}$ and $275 \mathrm{ka}$ for the base of the cores, respectively (Fig. 2). The slight shift towards older ages for the base of PG1351, with a new age of $275 \mathrm{ka}$ instead of $252 \mathrm{ka}$ (Nowaczyk et al., 2007), corresponds to the results of Lozkhin et al. (2007), suggesting that the lowermost part of the PG1351 pollen record represents MIS 8.

\section{Results and discussion}

Side-by-side plots of the rock magnetic parameters $\kappa_{\mathrm{LF}}$ and S-ratio, $\mathrm{TiO}_{2}$ content, CIA, TOC, and BSi versus age (Fig. 3) confirms the overall similarity in the sediment composition of cores PG1351 and Lz1024, which are already visible in the high-resolution records of magnetic susceptibility (Fig. 2).
Thus, the interpretation of the sediment variability of core PG1351 in terms of changes between oxic and anoxic conditions in the bottom waters can directly be transferred to core Lz1024, including the pattern of climate modes as defined by Melles et al. (2007). Downcore plots of the results of the cluster analysis for both cores in combination with this pattern are shown in Fig. 4. The lower number of data points in Fig. 4 compared to Fig. 3 is due to the re-sampling of the data sets used for cluster analysis with a lower resolution and the elimination of the turbidite layers in the records.

A total of 6 clusters were identified in both cores, with one cluster only present in the lowermost part of LZ1024. The main parameters defining the clusters are the magnetic susceptibility and the BSi and TOC contents (Fig. 4). Samples with low TOC values and high magnetic susceptibilities are marked either by black diamonds or green crosses, with the latter additionally defined by higher $\mathrm{TiO}_{2}$ values. Low magnetic susceptibilities in combination with high $\mathrm{BSi}$ values are typical for samples labelled with red triangles. Extremely high BSi values in some samples lead to the formation of a separate cluster (pink stars) (Fig. 4). The samples marked by blue squares have also low magnetic susceptibilities but in combination with low $\mathrm{BSi}$ and high $\mathrm{TiO}_{2}$ values. The sixth cluster, marked by yellow dots, is prominent for the 

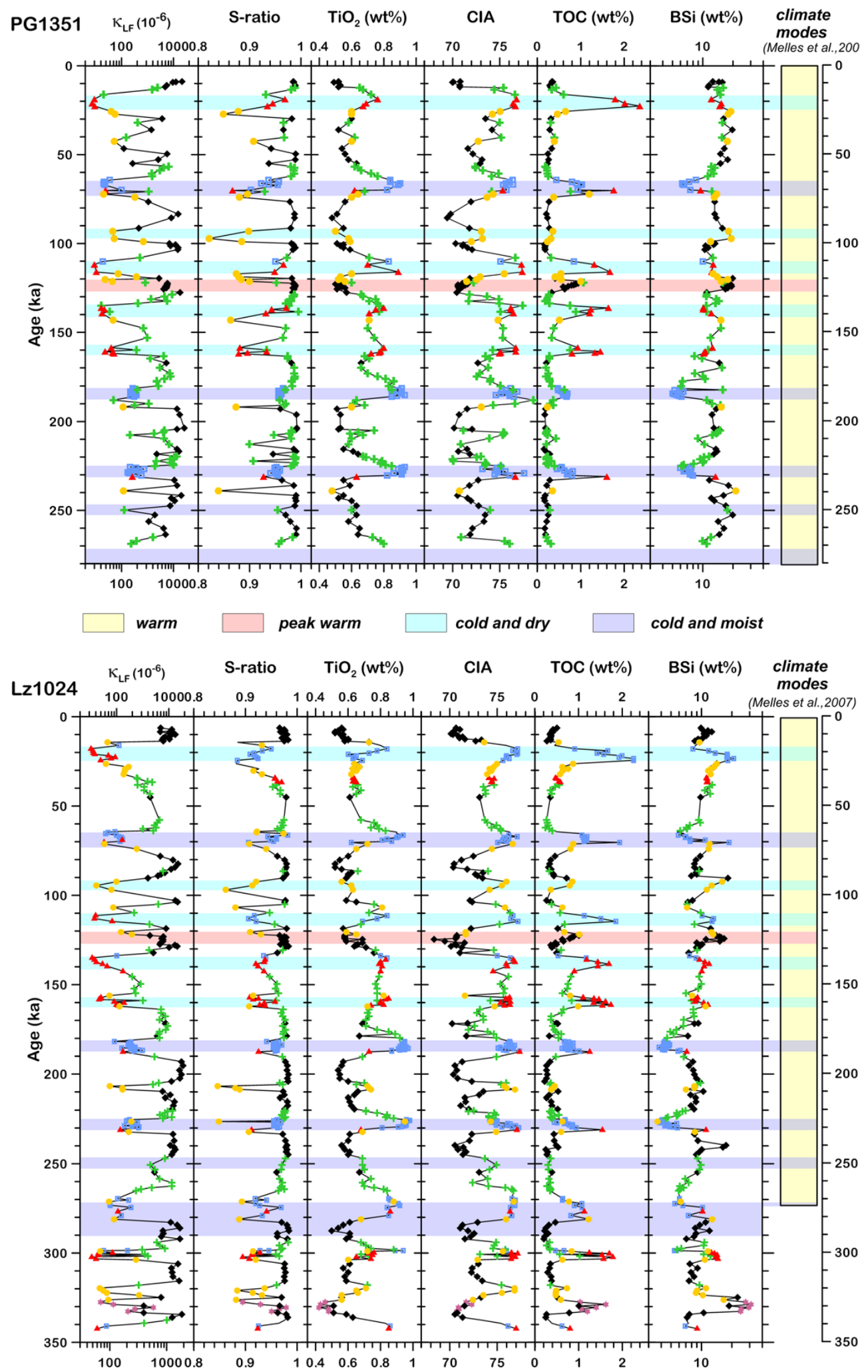

Fig. 4. Comparison of the results of the cluster analysis for core PG1351 and core Lz1024, with the pattern of climate modes defined for Lake El'gygytgyn (Melles et al., 2007) versus age. The ages of the climate zone boundaries were adjusted with regard to the new chronologies by Nowaczyk et al. $(2012,2013)$. The different symbols and colours denoting the five (six) clusters are superimposed on plots of the parameter records used for cluster calculation. For further details see text. 
low S-ratios whereas all other parameters are unremarkable (Fig. 4).

Out of the 6 clusters identified, two correspond very well with the climate modes cold and dry (red triangles) and cold and moist (blue squares). Full anoxic conditions, interpreted as a result of a permanent ice cover during cold climatic periods (Melles et al., 2007), are reflected for the time intervals 16.6-24.6, 64.8-73.2, 91.8-97.1, 110-116.9, 134.4-141.6, $157.1-162.8,181.2-187.5,224.9-231.3$ and $246.6-252.7 \mathrm{ka}$ (Fig. $4 \mathrm{a}$ and b). They are characterized by low $\kappa_{\mathrm{LF}}$ values, lowered S-ratios and high TOC values. The S-ratio, as a measure for the percentage of high coercitive magnetic minerals like hematite, decreases during intervals with increased reductive dissolution of the magnetically softer magnetite. BSi contents in the glacial sediments show high variability (Fig. 4). They are low in the sediments indicative for cold and moist climate, probably due to blanketing snow on the permanent ice cover that hampers light penetration into the surface waters and thus biogenic production (Melles et al., 2007). During cold and dry climates, consequently, rather high BSi contents are interpreted by a wide absence of snow cover. In the time intervals $181.2-187.5$ and $224.9-231.3 \mathrm{ka}$ the increase in TOC and decrease in $\kappa_{\mathrm{LF}}$ is less pronounced. Nevertheless, these sediments were deposited during cold periods, as can be deduced from the high CIA and $\mathrm{TiO}_{2}$ values (Fig. 4). Both parameters are found to be indicative for increased weathering during cold intervals (Minyuk et al., 2007), reflecting the rate of alteration and the amount of clastic material transported into the lake, respectively.

The three clusters, marked by black diamonds, yellow dots and green crosses, are representing warm-mode samples (Fig. 4). Interglacial/Interstadial sedimentation in Lake El'gygytgyn generally is characterized by high values in $\kappa_{\mathrm{LF}}$ and S-ratios and low values in $\mathrm{TOC}, \mathrm{TiO}_{2}$ and CIA. A very pronounced BSi peak occurs from 327.2 and $334.1 \mathrm{ka}$ (MIS 9.5), with opal contents of up to $40 \mathrm{wt}-\%$, being twice as high as in the rest of the profile, defining a separate cluster (pink stars) (Fig. 4). These high values suggest a distinctly higher biogenic production than in other interglacials, possibly due to a particularly warm climate. An increase in TOC is also found in the sediments formed between 120.1 and $127 \mathrm{ka}$ (MIS 5.5), however, the TOC peak is lower than during MIS 9.5 , and it is not associated with decreased $\kappa_{\mathrm{LF}}$ values and S-ratios, as indicators of enhanced dissolution of magnetite.

More detailed information on changes in the sediment composition of core PG1351 and Lz1024, especially on the transitional intervals between full oxic and anoxic conditions, is given by the results of the separate cluster analyses. Scatter plots of the different parameters, except for CIA, which shows variations comparable to those of $\mathrm{TiO}_{2}$ (Fig. 3), reveal in more detail how the clusters are defined (Fig. 5a to f). The best parameters to distinguish between the individual clusters are $\kappa_{\mathrm{LF}}$ and $\mathrm{TiO}_{2}$, representing the changes between oxic and anoxic conditions most effectively (Fig. 5b and e). Here it is clearly visible that the clusters are dis- tributed along two mixing lines, and could be grouped into three pairs as well. These pairs are representing the distinct warm climate mode samples: black (diamonds) and pink (stars) cluster, both cold mode samples: blue (squares) cluster and red (triangles) clusters, and yet unspecified warm climate mode samples: green (crosses) cluster and yellow (dots) cluster (Fig. 5e). These pairs have basically the same minerogenic and magnetic mineral content each, but with distinct differences in productivity, as expressed by both the opal and TOC values. The impact of the higher TOC and opal contents on the minerogenic components is visible as a shift in both, $\kappa_{\mathrm{LF}}$ and $\mathrm{TiO}_{2}$, towards lower values by means of increased dissolution and dilution, respectively. In the two separate clusters representing cold conditions the differences in productivity are attributed to the presence (blue squares = low productivity) or absence (red triangles = high productivity) of snow-covered ice (Melles et al., 2007), thus limiting the amount of sunlight available for primary production. During warm phases productivity is primarily affected by temperature, controlling the length of the ice-free period in summer (Melles et al., 2007). Therefore, the pink (stars) cluster is representing a peak warm phase contrasting normal warm phases marked by black diamonds (Fig. 5e).

Whereas the cluster representing the extreme climatic conditions are easily to address, the interpretation of the presence of two additional phases, marked by green crosses and yellow dots, becomes more difficult. They must be examined within the context of the mixing lines. The mixing line formed by the samples from the black (diamonds), the green (crosses) and the blue (squares) is also identifiable in the S-ratio and, with restrictions, in TOC (Fig. 5a and d). The black diamond end members of this line are characterized by high magnetic susceptibilities and high S-ratios, whereas both $\mathrm{TiO}_{2}$ and TOC are low. This combination reflects the oxic bottom-water conditions due to annual mixing during the ice-free period, in combination with a relative reduction of clastic sediment supply. Thus the magnetic mineral fraction is preserved, whereas the organic matter is degraded. At the other end of the mixing line, defined by the blue square cluster, sediment samples show the opposite behaviour with lower magnetic susceptibilities, on average higher TOC values and increased $\mathrm{TiO}_{2}$ content. These are characteristics for cold climates when anoxic conditions prevail at the lake bottom, leading to a good preservation of the organic material, whereas the magnetic fraction, mainly magnetite, is severely affected by dissolution (Nowaczyk et al., 2002). The BSi values are also low (Fig. 5c and f) since the biogenic productivity within the lake is limited, and suppressed mixing of the lake water and frozen soils in the catchment led to a depletion of nutrients. The samples from the green (crosses) clusters are then to be defined as reflecting transitional conditions, most probably a less pronounced warm phase, since the S-ratio, the TOC and BSi values are similar to those in the black diamond cluster. The comparable lower $\kappa_{\mathrm{LF}}$ values and higher $\mathrm{TiO}_{2}$ content are indicators for temporally 


\section{PG1351}

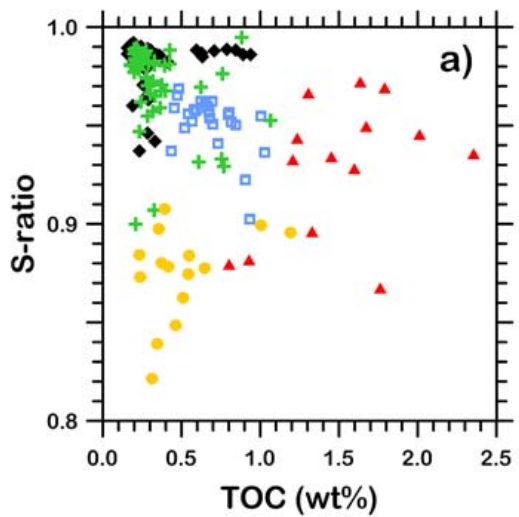

\section{Lz1024}

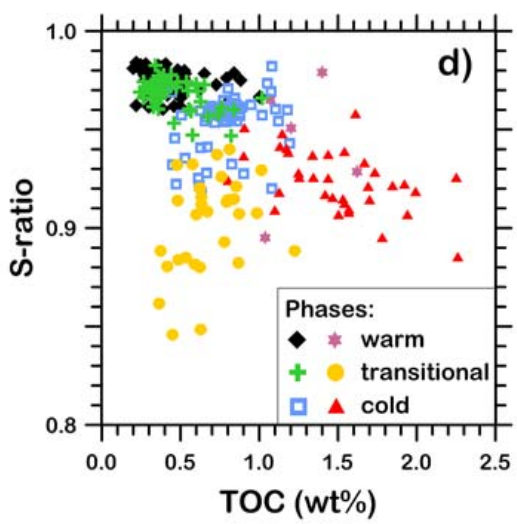

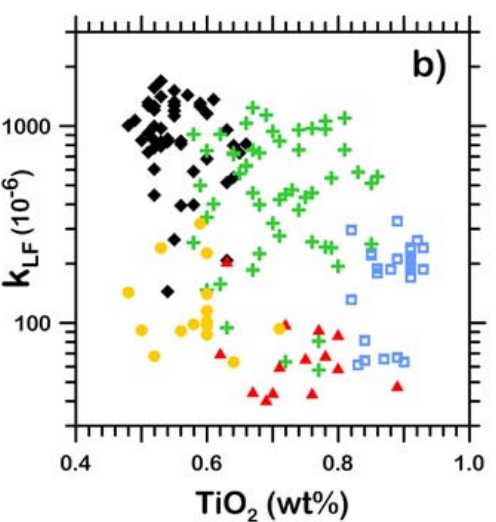
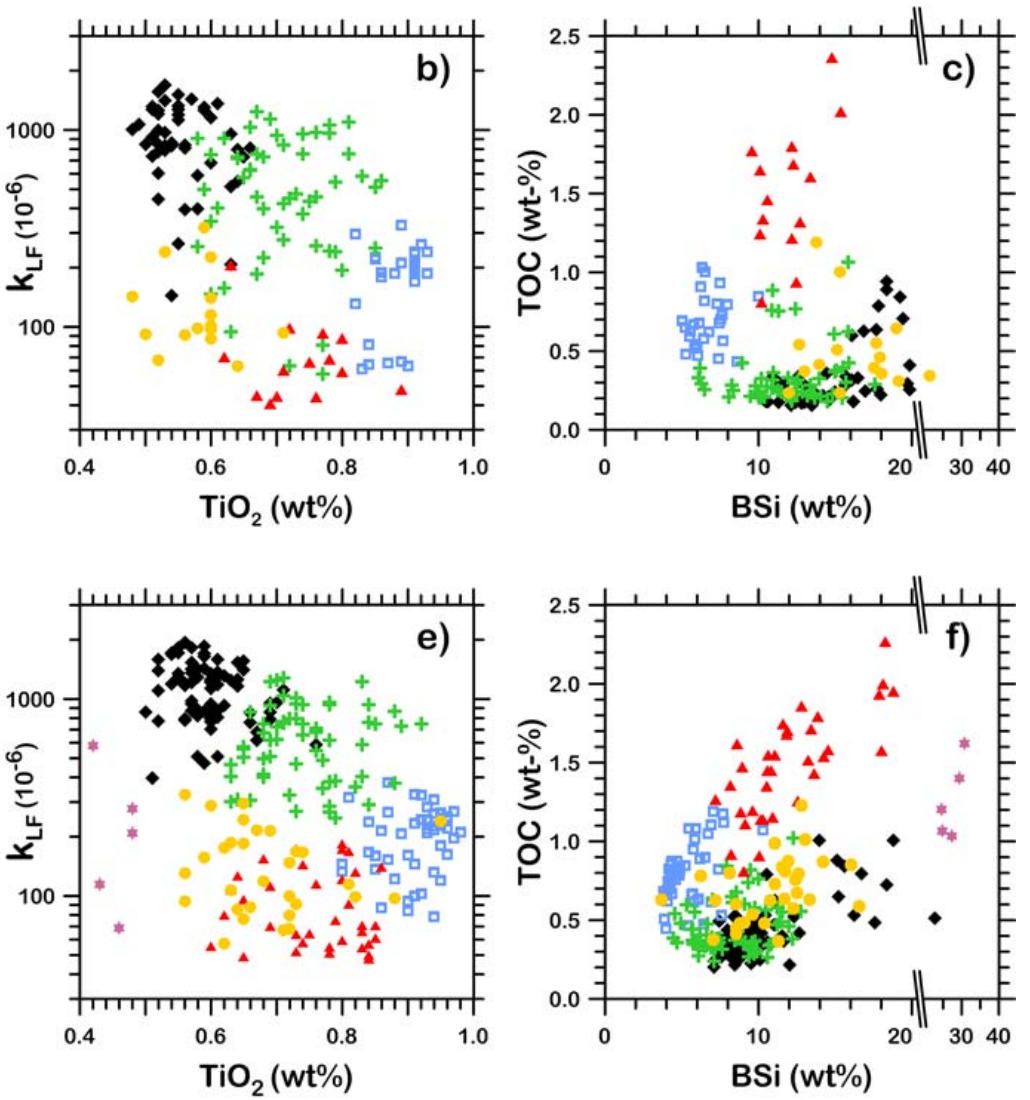

Fig. 5. Defining the sediment characteristics of the different climatic phases identified in PG1351 (a-c) and Lz1024 (d-f) by combining the parameters used for cluster analysis in a series of scatter plots. (a) and (d): TOC versus S-ratio (both are indicative for oxic/anoxic conditions); (b) and (e): $\mathrm{TiO}_{2}$ (lithogenic contribution) versus $\kappa_{\mathrm{LF}}$ (oxic/anoxic conditions); (c) and (f): BSi (diatom content) versus TOC (oxic/anoxic conditions). More detail on the subdivision of the samples into six clusters is given in the text.

anoxic conditions at the sediment-water interface and an increased clastic sediment supply, respectively. In core Lz1024 this grouping is more pronounced than in core PG1351, since the number of samples is higher (Fig. 5e).

The second mixing line includes the samples from the red (triangles), the yellow (dots) and the pink (stars) cluster (Fig. 5e). The samples from the latter cluster are located in the lowermost meter of the investigated sediment profile, only covered in core Lz1024 (Figs. 3 and 4). These samples have TOC values similar to those from the red (triangles) cluster but they have extremely high opal values, in combination with distinctively higher (lower) $\kappa_{\mathrm{LF}}\left(\mathrm{TiO}_{2}\right)$ values. The association of the BSi peak values with unusually high content of organic matter, as expressed by high TOC contents, and low values of $\kappa_{\mathrm{LF}}$ and S-ratio (Fig. 4) suggest that a particularly high flux of organic matter during this warm phase has generated at least seasonally anoxic conditions in the pore waters and subsequent dissolution of magnetic minerals. The red (triangles) are similar to the samples from the blue square cluster, but representing phases with a distinctly higher productivity, due to a wide absence of snow on the permanent ice cover. That is not only reflected by increased TOC and BSi values, but by the lowest $\kappa_{\mathrm{LF}}$ values, resulting from the increase in dissolution and dilution (Fig. 5e and f). The general trend in this mixing line is similar to the black-green-blue (diamonds-crosses-squares) line, but with a generally lower magnetic susceptibility level, which can be attributed to the higher rate of productivity and a better preservation of organic material. The samples from the yellow (dots) cluster then form, analogous to the green (crosses) cluster, a transitional group (Fig. 5a to f). Since the samples from the yellow dot cluster are characterized by the lowest S-ratios in the whole profile (Fig. 4), it must be assumed that the difference to the green (crosses) cluster is mainly due to increased dissolution of magnetite as a result of the slightly higher TOC values (Fig. 5a and b). Different runs of the statistical analysis, using varying parameter combinations, showed that the 6 clusters identified in cores PG1351 and Lz1024 are stable with only minor changes in the peripheral areas of the clusters. Reducing the number of clusters would lead to a fusion of the red (triangles) and yellow (dots) clusters, indicating that the samples from both groups 


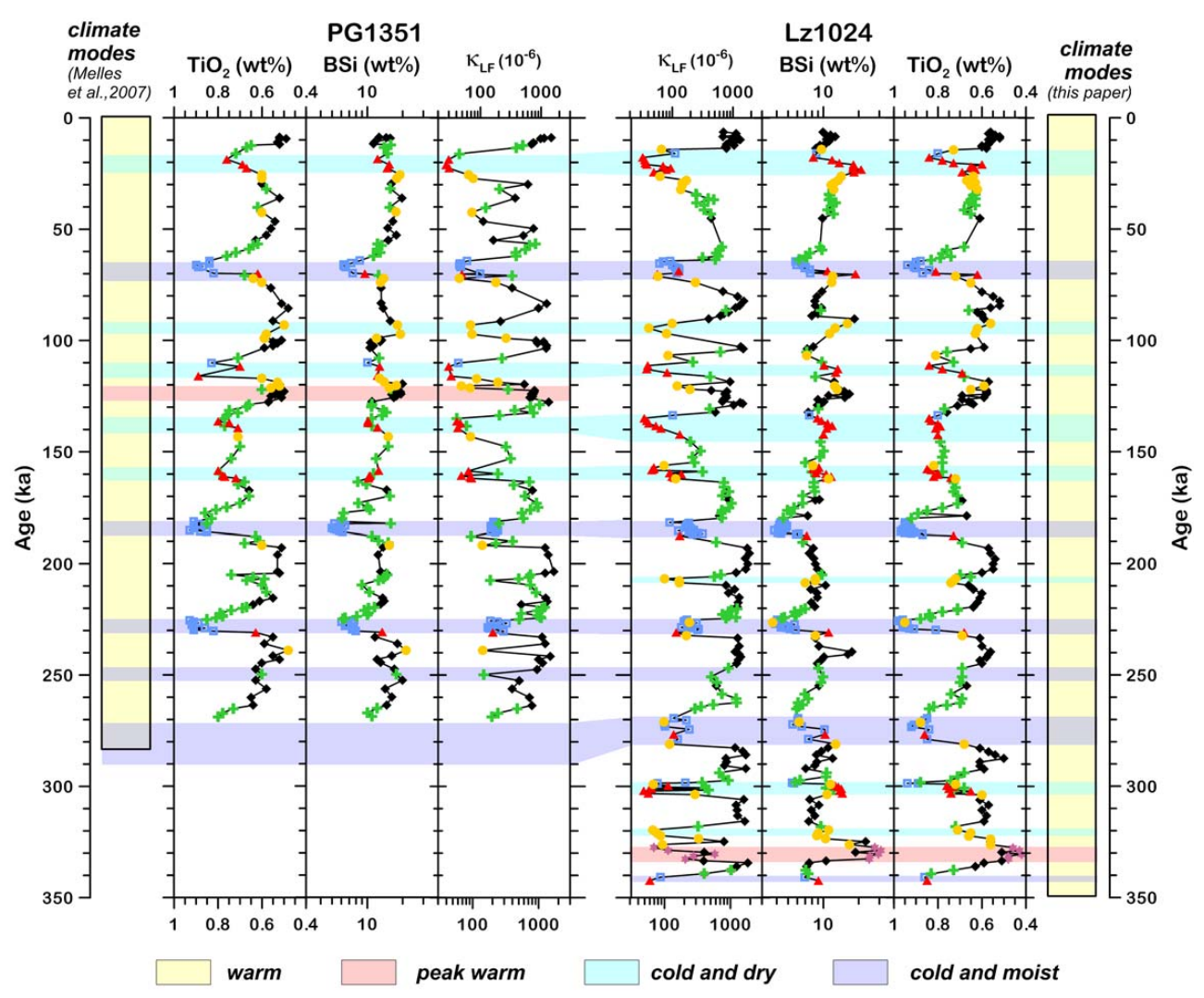

Fig. 6. Refining the boundaries of the climate modes at Lake El'gygytgyn by comparing the results of the cluster analysis for cores PG1351 and $\mathrm{Lz} 1024$ superimposed on the $\mathrm{TiO}_{2}$, the $\mathrm{BSi}$ and the magnetic susceptibility records versus age. Both $\mathrm{TiO}_{2}$ curves are plotted on inverted axes. For legend of the clusters see Fig. 5.

have partly overlapping sediment characteristics. Thus the samples from the yellow (dots) clusters are representing a preliminary or late stage of a cold phase, rather than of a warm phase. This interpretation is supported by the observation that the cold and dry phase from 91.8-97.1 ka (Melles et al., 2007), is marked by yellow dot samples in core PG1351 and Lz1024 as well (Fig. 4).

In concordance with this interpretation of the clusters the scheme of climate modes, as defined by Melles et al. (2007), was then refined and extended to $350 \mathrm{ka}$ in core Lz1024 (Fig. 6). Thus, three more phases dominated by dry and cold climate, one peak warm, and one cold and humid phase were identified. The decision to interpret the phase between 340.2 to $342.9 \mathrm{ka}$ as cold and humid rather than cold and dry is based on the relatively low TOC values, compared to the interval from 298.2 to $303.8 \mathrm{ka}$ (Fig. 3). The peak warm mode corresponding to MIS 5.5 (120.1 to $127 \mathrm{ka}$ ) was removed. There are some minor discrepancies between the results of the cluster analysis performed for core Lz1024 and the boundaries of the climatic phases defined in core PG1351 (Fig. 6). This can be explained by the higher resolution of core Lz1024, yet leading to an adaptation of the climate phase boundaries as shown in Fig. 6. For a further division of the cold phases, as it is suggested by the results of the clus- ter analysis, a minimum of two neighboured samples from the same cluster in both cores was requested, a precondition which is not met. With a less strict observance of these rules, a division of the cold phase from $64.8-73.2 \mathrm{ka}$ into one wet (64.8-69.9 ka) and one dry (69.9-73.2 ka) subphase (Fig. 6) would correspond to the results of Cherapanova et al. (2007), showing that a zone of low diatom abundance occurs between 63.2 and $67.5 \mathrm{ka}$, indicating a snow blanket on the perennial ice cover of the lake.

For a further interpretation of the clusters, the parameters $\kappa_{\mathrm{LF}}$, TOC and CIA were plotted on an age scale together with the marine oxygen isotope stack LR04 (Lisiecki and Raymo, 2005 ) and the cumulative summer (May to August) insolation at $67.5^{\circ} \mathrm{N}$ according to Laskar et al. (2004) (Fig. 7). Although the depth-age models of the El'gygytgyn sedimentary records of PG1351 and Lz1024 are both obtained by tuning to these two reference records (Nowaczyk et al., 2012, 2013), the similarity between the records reveals the strong coupling of Lake El'gygytgyn to external forcing processes. All the substages back to MIS 10 can easily be identified, best seen in the records reflecting the variability in the minerogenic components, which are $\kappa_{\mathrm{LF}}$ and CIA (Fig. 7). In the TOC record three of the cold substages, 7.2, 8.2 and 9.4, are not clearly visible, and the respective samples are neither 


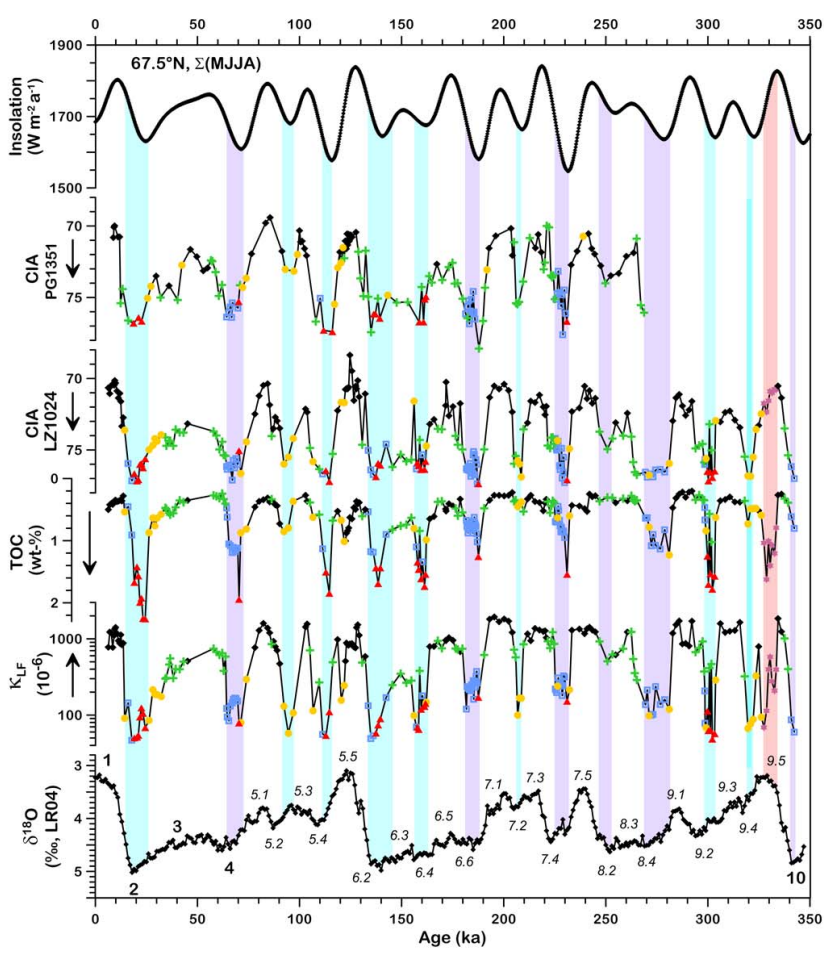

Fig. 7. Magnetic susceptibility $\left(\kappa_{\mathrm{LF}}\right)$, TOC, and CIA data of core Lz1024 composite versus time together with the CIA data of core PG1351, the summer insolation at $67.5^{\circ} \mathrm{N}$ according to Laskar et al. (2004, top) and the marine oxygen isotope $\left(\delta^{18} \mathrm{O}\right)$ stack LR04 by Lisiecki and Raymo (2005, bottom). Oxygen isotope stages are marked by bold numbers, substages by italicized numbers. The coloured symbols in the Lz1024 and PG1351 records denote the different clusters (see also Fig. 4). The shaded stripes denote climate modes at Lake El'gygytgyn: peak warm (pink), cold and dry (turquoise) and cold and moist (blue). For legend of the clusters see Fig. 5.

grouped into the blue (squares) cluster, nor the red (triangles) cluster, which would be typical for the cold phases, but in a transitional group. Nevertheless, the samples associated with substages 7.2 and 9.4 are grouped into the yellow (dots) cluster, already identified as being representative for an early stage of a cold phase. The climatic deterioration observed in the $\delta^{18} \mathrm{O}$ record during substage 8.2, however, had only a minor influence on the sediment composition in Lake El'gygytgyn (Fig. 7).

The most unexpected observation is that substage 5.5, the Eemian, cannot be distinguished from the other warm periods by means of cluster analysis, although it is known as the last peak warm phase before the beginning of the Holocene, with conditions similar to substage 9.5 (Fig. 7) (Miller et al., 2010). The latter clearly stands out, with its extremely high opal values, thus defining its own cluster (pink stars) (Fig. 5f). But this parameter and, based on the dilution effect, the $\mathrm{TiO}_{2}$ and, to a lesser degree, the $\kappa_{\mathrm{LF}}$ values, are the only parameters out of the normal (Figs. 6 and 7). For stage
5.5 none of the parameters presented show values that differ from those obtained for the other warm phases marked by black diamonds (Fig. 7). This corresponds to the results from ICDP core 5011-1 (Melles et al., 2012), showing that the sediment facies present during MIS 5.5 is typical for a wide range of glacial to interglacial settings, whereas MIS 9.5 belongs to a group of "super interglacials" that have distinctly laminated sediments and reflect particularly warm interglacials. Therefore, it must be assumed that the observed global raise in temperature during stage 5.5 affected the vegetation and the aquatic productivity, but not the conditions in the lake beyond the normal. Clear peaks in the amounts of tree pollen and diatoms, identified by Lozkhin et al. (2007) and Cherapanova et al. (2007), respectively, led to the conclusion that there was an increase in precipitation (Lozkhin et al., 2007). However, this did not affect the rate of weathering and amount of minerogenic material, because both are generally low during warm phases (Fig. 7). For a further discussion on this topic it would be necessary to have results of cluster analysis for the complete Holocene or stage 11 for comparison which are expected from the future work on the ICDP core 5011-1.

A second view on Fig. 7 reveals that nearly all warm phases marked by black diamonds are more strongly related to both the insolation and $\delta^{18} \mathrm{O}$ record than those marked by green crosses. The latter includes MIS 3, an interval that is not known for a marked global warming, but for a more pronounced regionality of climate change (Dawson, 1992) and the warm substages $6.3,6.5$, and 8.3. In the LR04 $\delta^{18} \mathrm{O}$ record, these intervals are characterized by much heavier values compared to the peaks marked by black diamonds in the El'gygytgyn records, that are MIS 1 and the warm substages in MIS 5, 7 and 9, which are associated with the lightest $\delta^{18} \mathrm{O}$ values. Naturally, there are some exceptions but the general trend is not in question (Fig. 7). This result indicates that it is possible to distinguish between three different types of warm climate modes in the sediments of Lake El'gygytgyn by means of cluster analysis, as implied by comparison to global records of climate variability. The primary reason for this lies in the high-latitude position of the lake, generating an environment that is very sensible to temperature changes. Complete mixing of the water body depends on ice-free conditions and therefore warm summer temperatures. Relative small changes in summer temperature will therefore severely effect the duration of the ice-free period, and thus the sediment composition by means of enhanced or decreased biogenic productivity, rate of mixing of the water body and hence, dissolution of either magnetite or organic matter.

\section{Conclusions}

Rock magnetic, biochemical and inorganic investigations on the $1660 \mathrm{~cm}$-long composite core Lz1024 from Lake El'gygytgyn revealed strong similarity in sediment 
composition with the neighbouring, $1291 \mathrm{~cm}$-long composite core PG1351. This allowed for extending and refining the existing pattern of climate variability from $250 \mathrm{ka}$ back to $350 \mathrm{ka}$. By means of cluster analysis it was possible to clearly differentiate between three of the four climate modes as defined by Melles et al. (2007). In addition to the warm, cold and dry, and cold and moist modes, two transitional modes were identified, representing the early stages of cold phases and slightly colder conditions during warm phases, respectively. Thus the gradual changes in the sedimentary composition as an indicator of available oxygen in the hypolimnion during glacial/non-glacial periods and the lack of mixing in the water column can be resolved in greater detail by using statistical approaches. But not every climate phase is detectable by means of cluster analysis alone, as was demonstrated by the samples between 120.1 and $127 \mathrm{ka}$ (MIS 5.5) that were not assigned to a peak warm mode as defined by Melles et al. (2007). The increased values in only one of the parameters used, the TOC, are not sufficient to single out this period. According to the statistical approaches, the MIS 9.5 has to be regarded as typical for "peak warm" instead, showing extreme values in at least two of the parameters, BSi and $\mathrm{TiO}_{2}$, used for cluster analysis (Figs. 3 and 7). Based on the sediment composition of core Lz1024 and on the results of cluster analysis, the succession of climate modes was then slightly modified, with a minimum of two samples defining a climatic phase. Comparison of the parameters $\kappa_{\mathrm{LF}}$, TOC and CIA, the marine oxygen isotope $\delta^{18} \mathrm{O}$ stack LR04, and the summer insolation at $67.5^{\circ} \mathrm{N}$, revealed that in the extended record from Lake El'gygytgyn all stages back to MIS 10, and most of the substages are clearly reflected in the statistical clustering of the records as visualized by the colour pattern of the cluster analysis. This also applies to the subdivision of the warm phases, since phases marked by black diamonds are more prominent in the insolation and the LR04 stack than those marked by green crosses. Phases marked by yellow dots are either assigned to transitions into colder stages and substages, or to these stages itself, thus confirming that the gradual changes in the sedimentary units could be resolved and transformed into detailed records of climate variability.

Acknowledgements. We would like to thank J. Brigham-Grette, A. Dehnert, G. Federov, O. Gluskkova, M. A. Haker, O. Juschus, M. Nolan, P. P. Overduin, S. Quart, V. Wennrich, and A. Zielke for their help in recovering the sediment cores from Lake El'gygytgyn during expeditions in 1998 and 2003. We thank Per Persson and the Chemistry Department at Umeå University for providing the FTIRS instrument. Financial support was kindly provided by the German Federal Ministry for Education and Research (BMBF grant nos. 03G0586 and 03G0642) and the Swedish Research Council (Vetenskapsrådet).

Edited by: T. Cook
The service charges for this open access publication have been covered by a Research Centre of the Helmholtz Association.

\section{References}

Asikainen, C. A., Francus P., and Brigham-Grette, J.: Sedimentology, clay mineralogy and grain-size as indicators of $65 \mathrm{ka}$ of climate change from El'gygytgyn Crater lake, Northeastern Siberia, J. Paleolimnol., 37, 105-122, 2007.

Bloemendal, J., King, J. W., Hall, F. R. and Doh, S.-J.: Rock magnetism of late Neogene and Pleistocene deep-sea sediments: Relationship to sediment source, diagenetic processes, and sediment lithology, J. Geophys. Res. 97, 4361-4375, 1992.

Brigham-Grette, J., Melles, M., Minyuk, P., and El'gygytgyn scientific Party: Overview and significanc of a 250 ka paleoclimate record from El'gygytgyn Crater lake, NE Russia, J. Paleolimnol., 37, 1-16, 2007.

Cherapanova, M. V., Snyder, J. A., and Brigham-Grette, J.: Diatom stratigraphy of the last $250 \mathrm{ka}$ at Lake El'gygytgyn, northeast Siberia, J. Paleolimnol., 37, 155-162, 2007.

Danielsson, Å., Cato, I., Carman, R., and Rahm, L.: Spatial clustering of metals in the sediments of the Skagerrak/Kattegat, Appl. Geochem., 14, 689-706, 1999.

Dawson, A. G.: Ice Age Earth - Late Quaternary geology and climate, Routledge, London, New York, 1992.

Forman, S. L., Pierson, J., Gómez, J., Brigham-Grette, J., Nowaczyk, N. R., and Melles, M.: Luminescence geochronology for sediments from Lake El'gygytgyn, northeast Siberia, Russia: constraining the timing of paleoenvironmental events for the past 200 ka, J. Paleolimnol., 37, 77-88, 2007.

Frank, U., Nowaczyk, N. R., and Negendank, J. F. W.: Rock magnetism of greigite bearing sediments from the Dead Sea, Israel, Geophys. J. Int., 168, 921-934, 2007.

Gurov, E. P. and Koeberl, C.: Shocked rocks and impact glasses from the El'gygytgyn impact structure, Russia, Meteor. Planet. Sci., 39, 1495-1508, 2004.

Juschus, O., Juschus, O., Preusser, F., Melles, M., and Radtke, U.: Applying SAR-IRSL methodology for dating fine-grained sediments from Lake El'gygytgyn, north-eastern Siberia, Quat. Geochron., 2,187-194, 2007.

Juschus, O., Melles, M., Gebhard, A. C., and Niessen, F.: Late Quaternary mass movement events in Lake El'gygytgyn, Northeastern Siberia, Sedimentology, 56, 2155-2174, 2009.

Laskar, J., Robutel, P., Joutel, F., Gastineau, M., Correia, A. C. M., and Levrard, B.: A long-term numerical solution for the insolation quantities of the Earth, Astron. Astrophys., 428, 261-285, 2004.

Layer, P. W.: Argon-40/Argon-39 age of the El'gygytgyn impact event, Chukotka, Russia, Meteor. Planet. Sci., 35, 591-599, 2000.

Lisiecki, L. E. and Raymo, M. E.: A Plio-Pleistocene stack of 57 globally distributed benthic $\delta^{18} \mathrm{O}$ records, Paleoceanography, 20, PA1003, doi:10.1029/2004PA001071, 2005.

Lozkhin, A. V., Anderson, P. M., Matrosova, T. V., and Minyuk, P. S.: The pollen record from El'gygytgyn lake: implications for vegetation and climate histories of northern Chukotka since the late middle Pleistocene, J. Paleolimnol., 37, 135-153, 2007. 
Melles, M., Minyuk, P., Brigham-Grette, J., and Juschus, O. (Eds.): The Expedition El'gygytgyn Lake 2003 (Siberian Arctic), Ber. Polarforsch. Meeresforsch., 509 pp., 2005.

Melles, M., Bringham-Grette, J., Glushkova, O. Y., Minyuk, P. S., Nowaczyk N. R., and Hubberten, H.-W.: Sedimentary geochemisty of core PG1351 from Lake El'gygytgyn - a sensitive record of climate variability in the East Siberian Arctic during the past three glacial-interglacial cycles, J. Paleolimnol., 37, 89104, 2007.

Melles, M., Grette, J., Minyuk, P. S., Nowaczyk, N. R., Wennrich, V., DeConto, R. M., Anderson, P. M., Andreev, A. A., Coletti, A., Cook, T. L., Hovi, E., Kukkonen, M., Lozhkin, A. V., Rosén, P., Tarasov, P., Vogel, H., and Wagner, B.: 2.8 Million Years of Arctic Climate Change from Lake El'gygytgyn, NE Russia, Science, 337, 315-320, 2012.

Miller, G. H., Brigham-Grette, J., Alley, R. B., Anderson, L., Bauch, H. A., Douglas, M. S. V., Edwards, M. E., Elias, S. A., Finney, B. P, Fitzpatrick, J. J., Funder, S. V., Herbert, T. D., Hinzman, L. D., Kaufman D. S., MacDonald, G. M., Polyak, L., Robock, A., Serreze, M.C., Smol, J. P., Spielhagen, R., White, J. W. C., Wolfe, A. P., and Wolff, E. W.: Temperature and precipitation history of the Arctic, Quaternary Sci. Rev., 29, 1679-1715, 2010.

Minyuk, P. S., Brigham-Grette, J., Melles, M., Borkhodoev, V. Y., and Glushkova O. Y.: Inorganic geochemistry of El'gygytgyn Lake sediments (northeastern Russia) as an indicator of paleoclimatic change for the last $250 \mathrm{kyr}$, J. Paleolimnol., 37, 123-133, 2007.

Müller, P. J. and Schneider, J.: An automated leaching method for the determination of opal in sediments and particulate matters, Deep-Sea Res., 40, 425-444, 1993.

Nolan, M. and Brigham-Grette, J.: Basic hydrology, limnology, and meterology of modern Lake El'gygytgyn, Siberia, J. Paleolim., 37, 17-35, 2007.
Nowaczyk, N. R., Minyuk, P., Melles, M., Brigham-Grette, J., Glushkova, O., Nolan, M., Lozhkin, A. V., Stetsenko, T. V., Andersen, P. M., and Forman, S. L.: Magnetostratigraphic results from impact crater Lake El'gygytgyn, northeastern Siberia: a 300 kyr long high-resolution terrestrial paleoclimatic record from the Arctic, Geophys. J. Int., 150, 109-126, 2002.

Nowaczyk, N. R., Minyuk, P., and Melles, M.: A revised age model for core PG1351 from Lake El'gygytgyn, Chukotka, based on magnetic susceptibility variations tuned to northern hemisphere insolation variations, J. Paleolimnol., 37, 65-76, 2007.

Nowaczyk, N. R., Haltia, E. M., Ulbricht, D., Wennrich, V., Sauerbrey, M. A., Rosén, P., Vogel, H., Francke, A., Meyer-Jacob, C., Andreev, A. A., and Lozhkin, A. V.: Chronology of Lake El'gygytgyn sediments, Clim. Past Discuss., 9, 3061-3102, doi:10.5194/cpd-9-3061-2013, 2013.

Rosén, P., Vogel, H., Cunningham, L., Reuss, N., Conley, D. J., and Persson, P.: Fourier transform infrared spectroscopy, a new method for rapid determination of total organic and inorganic carbon and biogenic silica concentration in lake sediments, J. Paleolimnol., 43, 247-259, 2010a.

Rosén, P., Vogel, H., Cunningham, L., Hahn, A., Hausmann, S., Pienitz, R., Zolitschka, B., Wagner, B., and Persson, P.: A universally applicable model for the quantitative determination of lake sediment composition using Fourier transform infrared spectroscopy, Environ. Sci. Technol., 45, 8858-8865, 2010b.

Simeonov, V., Massart, D. L., Andreev, G., and Tsakovski, S.: Assessment of metal pollution based on multivariate statistical modeling of "hot spot" sediments from the Black Sea, Chemosphere, 41, 1411-1417, 2000. 